\title{
Integrating cytokines and angiogenic factors and tumour bulk with selected clinical criteria improves determination of prognosis in advanced renal cell carcinoma
}

\author{
A J Zurita ${ }^{*}{ }^{1}$, R C Gagnon ${ }^{2}$, Y Liu ${ }^{3}, \mathrm{H} \mathrm{T} \mathrm{Tran}{ }^{1}$, R A Figlin ${ }^{4}$, T E Hutson ${ }^{5,6,7}$, A M D'Amelio Jr ${ }^{8}$, \\ C N Sternberg ${ }^{9}$, L N Pandite $^{10}$ and J V Heymach ${ }^{1}$ \\ ${ }^{1}$ MD Anderson Cancer Center, 1515 Holcombe Blvd., Houston, TX 77030, USA; ${ }^{2}$ Bristol-Myers Squibb Company, PO Box 5400, \\ J42-05, Princeton, NJ 08543, USA; ${ }^{3}$ Pfizer Translational Oncology, 10646 Science Center Dr, San Diego, CA 92121, USA; ${ }^{4}$ Cedars- \\ Sinai Medical Center, Samuel Oschin Comprehensive Cancer Institute, Los Angeles, CA 90048, USA; ${ }^{5}$ US Oncology/McKesson \\ Specialty Health, The Woodlands, TX, USA; ${ }^{6}$ Texas Oncology, Dallas, TX, USA; ${ }^{7}$ Baylor Sammons Cancer Center, Dallas, TX 75246, \\ USA; ${ }^{8}$ Novartis Pharmaceuticals Corporation, East Hanover, NJ 07936, USA; ${ }^{9}$ Department of Medical Oncology, San Camillo and \\ Forlanini Hospitals, Rome 00152, Italy and ${ }^{10}$ Adaptimmune LLC, Philadelphia, PA 19112, USA
}

Background: In two clinical trials of the vascular endothelial growth factor (VEGF) receptor inhibitor pazopanib in advanced renal cell carcinoma (mRCC), we found interleukin-6 as predictive of pazopanib benefit. We evaluated the prognostic significance of candidate cytokines and angiogenic factors (CAFs) identified in that work relative to accepted clinical parameters.

Methods: Seven preselected plasma CAFs (interleukin-6, interleukin-8, osteopontin, VEGF, hepatocyte growth factor, tissue inhibitor of metalloproteinases (TIMP-1), and E-selectin) were measured using multiplex ELISA in plasma collected pretreatment from $343 \mathrm{mRCC}$ patients participating in the phase 3 registration trial of pazopanib vs placebo (NCT00334282). Tumour burden (per sum of longest diameters (SLD)) and 10 other clinical factors were also analysed for association with overall survival (OS; based on initial treatment assignment).

Results: Osteopontin, interleukin-6, and TIMP-1 were independently associated with OS in multivariable analysis. A model combining the three CAFs and five clinical variables (including SLD) had higher prognostic accuracy than the International Metastatic Renal Cell Carcinoma Database Consortium criteria (concordance-index 0.75 vs 0.67 , respectively), and distinguished two groups of patients within the original intermediate risk category.

Conclusions: A prognostic model incorporating osteopontin, interleukin-6, TIMP-1, tumour burden, and selected clinical criteria increased prognostic accuracy for OS determination in $\mathrm{MRCC}$ patients.

Although therapies targeting the vascular endothelial growth factor (VEGF) and the mechanistic target of rapamycin were developed based on understanding the biology of advanced renal cell carcinoma (mRCC), no biomarkers have yet been validated that relate these biological aspects with the individual patient's tumour and need for specific therapy. Although promising tumour-tissue

*Correspondence: Dr AJ Zurita; E-mail: azurita@mdanderson.org.

Previous presentation: Portions of the data were presented at the ASCO 2014 Annual Meeting (abstract/poster 4582).

Received 13 January 2017; revised 28 April 2017; accepted 7 June 2017; published online 6 July 2017

(C) 2017 Cancer Research UK. All rights reserved 0007-0920/17 
and blood-derived markers exist (Jonasch et al, 2012; Maroto and Rini, 2014), prognosis for mRCC patients is still largely based upon algorithms utilising clinical features.

In mRCC, many clinical variables have been proposed as prognostic, and some have become validated. The most current prognostic model was presented by the International Metastatic RCC Database Consortium (IMDC) in 2009 (Heng et al, 2009). Six variables (two clinical (Karnofsky performance status (KPS) and diagnosis-to-treatment time), four laboratory-based (haemoglobin, corrected calcium, neutrophils, and platelets)) were used to identify three prognostic groups in which different overall survival (OS) outcomes depend on the number of individual risk factors. This model has also been externally validated and found to compare favourably to four other earlier models, including the widely used Memorial Sloan-Kettering Cancer Center (MSKCC) criteria (Motzer et al, 2002; Choueiri et al, 2007; Escudier et al, 2008; Manola et al, 2011; Heng et al, 2013). Those models, however useful, have reached a ceiling in ability to prognosticate. One possible explanation is that most of the current risk factors represent collateral consequences of biological processes rather than driving forces. Hence, there is a need to incorporate genetic and molecular biomarkers relevant to the natural history and treatment of mRCC into prognostic modelling.

Cytokines and angiogenic factors (CAFs) are broadly profiled to screen for and identify candidate soluble prognostic and predictive markers in RCC (Tran et al, 2012; Zurita et al, 2012). In mRCC patients with Eastern Cooperative Oncology Group (ECOG) PS 0 to 1 who were treated in clinical trials of pazopanib, we found interleukin-6 as predictive of improved relative progression-free survival (PFS) benefit from pazopanib compared with placebo (Tran et al, 2012). Moreover, high osteopontin and interleukin-6 concentrations conferred poor PFS risk independent of clinical factors (Zurita-Saavedra et al, 2012), leading us to hypothesise that some CAFs may be independently prognostic for OS and likely to substantially enhance prognostic ability over established criteria. In this analysis, we evaluated the prognostic significance of CAFs for OS together with established clinical parameters (IMDC, MSKCC) and tumour burden.

\section{MATERIALS AND METHODS}

Patient data. The study design has been described previously (Sternberg et al, 2010; Sternberg et al, 2013). Pretreatment plasma samples were obtained from patients with mRCC enrolled in the phase 3 registration study of pazopanib vs placebo (VEG105192, ClinicalTrials.gov, NCT00334282; details at: https:// clinicaltrials.gov/ct2/show/NCT00334282) and provided written informed consent (Tran et al, 2012; Sternberg et al, 2013). This analysis used baseline ECOG PS instead of KPS.

Analysis of CAFs. Plasma separation methodology is included in Supplementary Online Material. The analysis was completed at a Clinical Laboratory Improvement Amendments (CLIA)-certified facility for seven CAFs (interleukin-6, interleukin-8, E-selectin, hepatocyte growth factor (HGF), VEGF-A (henceforth VEGF), osteopontin, and tissue inhibitor of metalloproteinase-1 (TIMP-1)) with the SearchLight Protein Array (Aushon Biosystems, Billerica, MA, USA), as previously described (Tran et al, 2012). These seven were identified from 17 CAFs screened in a previous analysis (Tran et al, 2012).

Statistical analysis. Clinical variables and candidate CAFs associated with poor survival were identified using univariable, multivariable, and stepwise Cox proportional hazard models. When testing for proportional hazards, a time-dependent covariate representing interaction between the original covariate and time was used, and the interaction term was tested for statistical significance. OS results were stratified by treatment assignment at randomisation. Pre-treatment SLD per Response Evaluation Criteria in Solid Tumors was assessed as a $\log _{2}$-transformed continuous variable. Median plasma levels for each CAF were used as the cutoff for high $v s$ low analysis, based on the results of sensitivity analyses (Tran et al, 2012) and to facilitate clinical application. Concordance (C)-index for each model (median SLD levels were used as the cutoff for high $v s$ low analysis in C-index models) was determined as described by Harrell et al (1996). Kaplan-Meier analysis was utilised to assess risk groups. Association between CAFs, SLD, and IMDC parameters was assessed using Spearman's correlation coefficient $(R)$.

All analyses were post hoc and conducted in SAS (v9.2 or later) or $\mathrm{R}$ (v3.1.0). $P$-values $<0.05$ were considered statistically significant in all models. All tests of statistical significance were twosided.

\section{RESULTS}

Patient disease characteristics and outcomes. Of 435 patients with mRCC enrolled in VEG105192 (Sternberg et al, 2010), 343 (79\%) with complete information on CAFs at baseline were available for this analysis (pazopanib, $n=225$; placebo, $n=118$; Figure 1). At the cutoff date, 322 patients (94\%) had discontinued treatment and 114 (33\%) were alive. Of the IMDC factors, corrected serum calcium data were missing for 19 patients $(5.5 \%)$. Because only $5 \%$ presented with hypercalcemia and we found no effect for this variable in sensitivity analyses conducted ad hoc, we considered those 19 patients as having normal calcium concentrations. A total of 310 patients had data available on diagnosis-totreatment time: $86(27.7 \%)$ had favourable, $176(56.8 \%)$ had intermediate, and $48(15.5 \%)$ had poor risk according to IMDC prognostic criteria. Baseline characteristics (Table 1) and PFS were similar between the patients included in this analysis and the complete clinical trial set.

Clinical factors and OS. Final OS in the treatment arms was comparable in this study: pazopanib-treated patients, 22.9 months (95\% confidence interval (CI), 20.2-25.4), and placebo-treated patients, 20.9 months (95\% CI, 15.6-28.8), hazard ratio (HR) 0.91 (95\% CI, 0.71-1.16; $P=0.224$ ). The similar survival results are likely due to the high rate (54\%) of patients' crossover from the placebo arm to pazopanib at the time of progression (Sternberg et al, 2013). Of the 11 clinical variables tested (including treatment; Table 2), we found all but corrected serum calcium to be determinants of OS in univariable analysis (Table 3). However, only SLD, serum LDH > $1.5 \times$ upper limit of normal (ULN), high neutrophil count, low serum haemoglobin, and ECOG PS 1 (vs 0 ) were confirmed as predictors of shorter OS in a multivariable stepwise analysis (Table 3). Diagnosis-to-treatment time $<1$ year was also a significant factor in the subset with 310 patients $(P<0.0001)$. No effect on gender or ethnic groups was observed.

Prognostic value of individual CAFs and model integration. In our original evaluation of CAFs in the biomarker population based on treatment assignment at initial randomisation, six of the seven CAF candidates (all but E-selectin) were found to be prognostic for OS in both the pazopanib and placebo patient sets using univariable analysis (Tran et al, 2012). In the stepwise multivariable analysis that included treatment and the clinical criteria above, we assessed the prognostic significance of each CAF individually. Plasma levels of five CAFs (osteopontin, interleukin6, TIMP-1, HGF, and interleukin-8) remained independently prognostic in the 343-patient set, and four CAFs (osteopontin, interleukin-6, TIMP-1, and interleukin-8) did so when diagnosisto-treatment time $<1$ year was included (Supplementary Table 1). 


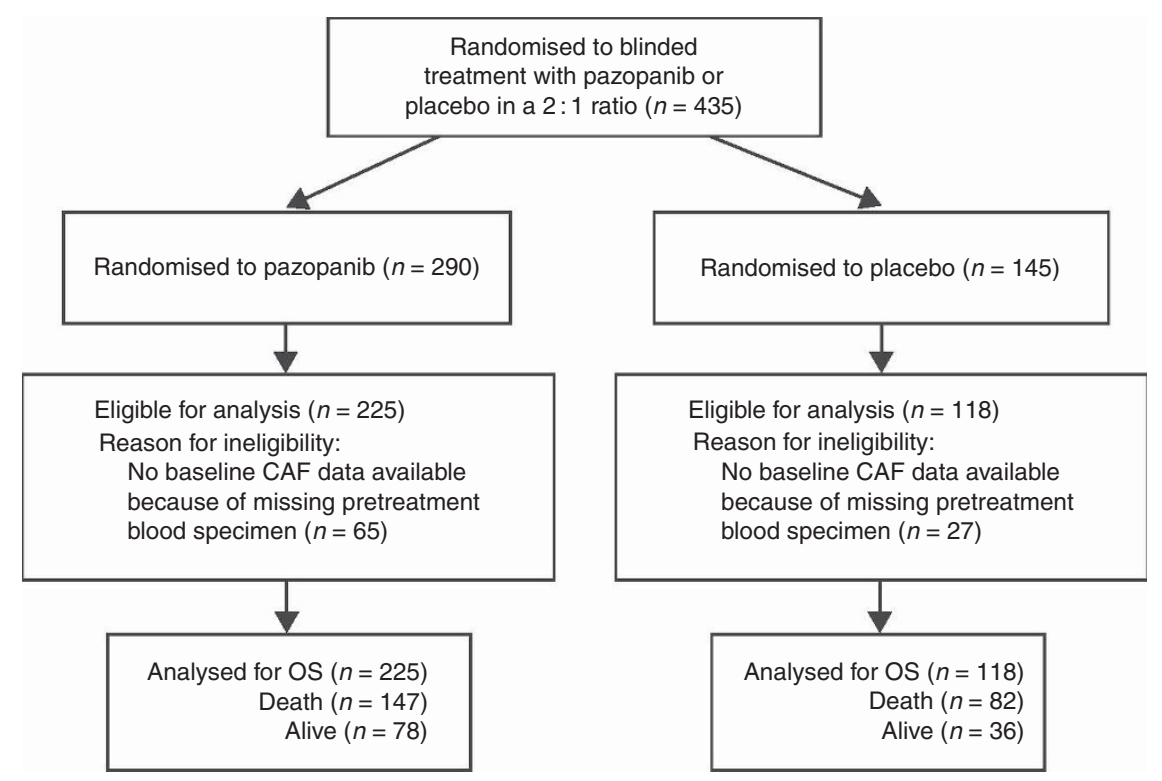

Figure 1. CONSORT diagram. $C A F=$ cytokines and angiogenic factors; OS=overall survival.

Table 1. Patient demographics and disease characteristics

\begin{tabular}{|c|c|c|c|c|}
\hline & \multicolumn{2}{|c|}{ Overall } & \multicolumn{2}{|c|}{ CAF subset } \\
\hline Median age, years (range) & $59(28-85)$ & $60(25-81)$ & $59(31-85)$ & $59.5(25-81)$ \\
\hline $\begin{array}{l}\text { Race, } n(\%) \\
\text { White } \\
\text { Asian } \\
\text { Black } \\
\text { Other } \\
\text { Median time since initial diagnosis, months (range) }\end{array}$ & $\begin{aligned} 252 & (87) \\
36 & (12) \\
1 & (<1) \\
1 & (<1) \\
15.7 & (0-184)\end{aligned}$ & $\begin{aligned} & 122(84) \\
& 23(16) \\
& 0 \\
& 0 \\
& 13.8(1.0-152)\end{aligned}$ & $\begin{aligned} & 196(87) \\
& 28(12) \\
& 0 \\
& 1(<1) \\
& 15.6(0.7-184)\end{aligned}$ & $\begin{array}{l}97(82) \\
21(18) \\
0 \\
0 \\
13.8(0.8-148)\end{array}$ \\
\hline $\begin{array}{l}\text { ECOG performance status, } n(\%) \\
0 \\
1 \\
\end{array}$ & $\begin{array}{l}123(42) \\
167(58) \\
\end{array}$ & $\begin{array}{l}60(41) \\
85(59) \\
\end{array}$ & $\begin{array}{r}93(41) \\
132(59) \\
\end{array}$ & $\begin{array}{l}44(37) \\
74(63) \\
\end{array}$ \\
\hline $\begin{array}{l}\text { MSKCC risk category, } n(\%) \\
\text { Favourable } \\
\text { Intermediate } \\
\text { Poor } \\
\text { Unknown }\end{array}$ & $\begin{array}{c}113(39) \\
159(55) \\
9(3) \\
9(3)\end{array}$ & $\begin{array}{l}57(39) \\
77(53) \\
5(3) \\
6(4)\end{array}$ & $\begin{aligned} & 88(39) \\
& 124(55) \\
& 7(3) \\
& 6(3)\end{aligned}$ & $\begin{array}{l}45(38) \\
63(53) \\
5(4) \\
5(4)\end{array}$ \\
\hline $\begin{array}{l}\text { Prior systematic treatment, } n(\%) \\
\text { Treatment naive } \\
\text { Cytokine pretreated } \\
\text { PFS, weeks }(95 \% \mathrm{Cl})\end{array}$ & $\begin{array}{l}155(53) \\
135(47) \\
40.1(32.1-56.1)\end{array}$ & $\begin{aligned} 78(54) \\
67(46) \\
18.1(12.1-18.1)\end{aligned}$ & $\begin{array}{l}119(53) \\
106(47) \\
39.6(32.1-48.1)\end{array}$ & $\begin{aligned} 59(50) \\
59(50) \\
13.4(12.1-19.1)\end{aligned}$ \\
\hline
\end{tabular}

A complete multivariable model incorporating all CAFs, treatment, and clinical variables showed that high ( $>$ median) concentrations of three CAFs (osteopontin $\left(>191627 \mathrm{pg} \mathrm{ml}^{-1}\right.$ ), interleukin-6 (>13.07 $\left.\mathrm{pg} \mathrm{ml}^{-1}\right)$, and TIMP-1 [>676070 $\left.\left.\mathrm{pg} \mathrm{ml}^{-1}\right]\right)$ and four clinical factors (LDH $>1.5 \times \mathrm{ULN}$, SLD, elevated neutrophil counts, and ECOG PS 1) were independent predictors of poor OS (Table 4). The concentrations of the three CAFs were not significantly different in treatment-naive $(n=178)$ vs cytokine pretreated $(n=165)$ patients (median osteopontin $197.9 \mathrm{pg} \mathrm{ml}^{-1}$ vs $180.6 \mathrm{pg} \mathrm{ml}^{-1}, P=0.11$; interleukin-6 $12.8 \mathrm{pg} \mathrm{ml}^{-1}$ vs $13.5 \mathrm{pg} \mathrm{ml}^{-1}$, $P=0.99$; and TIMP-1 $638.6 \mathrm{pg} \mathrm{ml}^{-1}$ vs $693.8 \mathrm{pg} \mathrm{ml}^{-1}, P=0.21$ ). The variable 'treatment' did not reach significance $(P=0.06$; HR, 0.77 ); however, diagnosis-to-treatment time $<1$ year was significant $(P<0.0001)$ in the subset of 310 patients for whom it was available (Table 4).
In the new prognostic 'CAF model' (eight variables, including diagnosis-to-treatment time), the group with very favourable prognosis (no risk factors) comprised 16 patients (5.2\%) with median OS not reached (NR; 95\% CI, 27.1 months-NR). The following two new groups emerged: favourable (1-2 adverse factors; 107 patients $(34.5 \%)$ ) and intermediate (3-4; 98 patients $(31.6 \%))$, with a median OS of 38.9 (95\% CI, 30-7-NR) and 19.4 months (95\% CI, 15.4-22.9), respectively. The poor prognosis group ( $\geqslant 5$ risk factors) comprised 89 patients $(28.7 \%$ ) with a median OS of 7.7 months (95\% CI, 5.3-10.9). There were clear distinctions in OS among risk groups (log-rank $P<0.0001)$. Patient distribution and OS according to the IMDC risk categories and the new CAF model are shown in Figure 2A and B, respectively.

The predictive performance of our final model was internally validated using a bootstrap resampling procedure $(n=300)$ with 
Table 2. Patient distribution as related to components of IMDC and/or MSKCC classifications

\begin{tabular}{|c|c|}
\hline Variable, $n$ (\%) & Patients $(N=343)^{a}$ \\
\hline ECOG PS 1 & $206(60)$ \\
\hline Diagnosis-to-treatment time $<1$ year & $134(43)$ \\
\hline Haemoglobin <LLN & $156(46)$ \\
\hline Platelets > ULN & $73(21)$ \\
\hline Neutrophils > ULN & $62(18)$ \\
\hline $\mathrm{LDH}>1.5 \times \mathrm{ULN}$ & $33(10)$ \\
\hline Calcium > ULN & $16(5)$ \\
\hline Bone metastases & $99(29)$ \\
\hline Number of metastasis sites $\geqslant 1$ & $276(80)$ \\
\hline \multicolumn{2}{|c|}{ 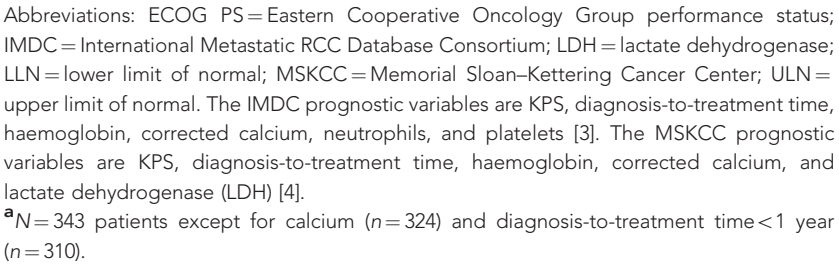 } \\
\hline
\end{tabular}

\begin{tabular}{|c|c|c|c|}
\hline & HR & $95 \% \mathrm{Cl}$ & $P$-value \\
\hline \multicolumn{4}{|l|}{ Univariable covariate model $^{a}$} \\
\hline ECOG PS 1 vs 0 & 1.827 & $1.385-2.412$ & $<0.0001$ \\
\hline Diagnosis-to-treatment time $<1$ year & 1.900 & $1.443-2.503$ & $<0.0001$ \\
\hline Haemoglobin <LLN & 1.941 & $1.495-2.521$ & $<0.0001$ \\
\hline Neutrophils > ULN & 2.074 & $1.523-2.826$ & $<0.0001$ \\
\hline $\mathrm{LDH}>1.5 \times \mathrm{ULN}$ & 3.265 & $2.171-4.909$ & $<0.0001$ \\
\hline Calcium > ULN & 1.679 & $0.958-2.942$ & 0.0701 \\
\hline Bone metastases & 1.357 & $1.025-1.796$ & 0.0332 \\
\hline Number of metastasis sites $>1$ vs $\leqslant 1$ & 2.192 & $1.492-3.221$ & $<0.0001$ \\
\hline Baseline SLD & 1.532 & $1.351-1.738$ & $<0.0001$ \\
\hline Platelets $>$ ULN & 1.528 & $1.131-2.063$ & 0.0057 \\
\hline \multicolumn{4}{|l|}{ Multivariable stepwise OS model } \\
\hline ECOG PS 1 vs 0 & 1.368 & $1.024-1.826$ & 0.0338 \\
\hline Diagnosis-to-treatment time $<1$ year & 1.892 & $1.422-2.519$ & $<0.0001$ \\
\hline Haemoglobin <LLN vs others & 1.565 & $1.191-2.056$ & 0.0013 \\
\hline Neutrophils > ULN & 1.85 & $1.352-2.533$ & 0.0001 \\
\hline LDH $>1.5 \times$ ULN vs others & 2.044 & $1.348-3.101$ & 0.0008 \\
\hline Baseline SLD & 1.395 & $1.234-1.577$ & $<0.0001$ \\
\hline \multicolumn{4}{|c|}{$\begin{array}{l}\text { Abbreviations: } \mathrm{Cl}=\text { confidence interval; ECOG PS = Eastern Cooperative Oncology Group } \\
\text { performance status; } \mathrm{HR}=\text { hazard ratio; } L D H=\text { lactate dehydrogenase; } L L N=\text { lower limit of } \\
\text { normal; } \mathrm{OS}=\text { overall survival; } \mathrm{SLD}=\text { sum of longest diameters; } \mathrm{ULN}=\text { upper limit of normal. } \\
{ }^{\mathrm{a}} \text { Treatment variable included in the model; } N=343 \text {, except for diagnosis-to-treatment time } \\
<1 \text { year }(n=310) \text {. }\end{array}$} \\
\hline
\end{tabular}

the same selection criteria as the original model (Table 4). We found $>50 \%$ frequency for each of the included variables except for TIMP-1 (46\%) in the 343-patient set (TIMP-1 came up 68\% of the time in $n=310)$. The $\mathrm{C}$-index for our new CAF model $(n=310)$ was 0.75 (95\% CI, 0.70-0.79).

Comparative assessment of new CAF model with IMDC criteria. The C-index for our CAF model was substantially higher than that for the IMDC $(0.67$ (95\% CI, 0.63-0.72)). To assess whether the prognostic ability of the IMDC criteria could be improved by the independently prognostic CAFs and SLD, we reevaluated the effect of the inclusion of these variables and recalculated the C-index. As expected, the C-statistic improved to 0.71 (95\% CI, 0.67-0.75) with interleukin-6 and osteopontin, to 0.72 (95\% CI, 0.68-0.77) with the three CAFs, and to 0.73 (95\% CI, 0.69-0.77) with the three CAFs and SLD. The C-index of IMDC criteria plus SLD was 0.70 (95\% CI, 0.66-0.74). Similar to the effect
Table 4. Stepwise model of independent predictors of overall survival with treatment, CAFs, and clinical risk factors, and bootstrap resampling for internal validation

\begin{tabular}{|c|c|c|c|}
\hline & HR & $95 \% \mathrm{Cl}$ & $P$-value \\
\hline \multicolumn{4}{|l|}{ Variable $(N=343)^{a}$} \\
\hline IL-6 & 1.563 & $1.156-2.114$ & 0.0037 \\
\hline TIMP-1 & 1.367 & $1.029-1.817$ & 0.0311 \\
\hline OPN & 1.485 & $1.066-2.068$ & 0.0192 \\
\hline ECOG PS 1 vs 0 & 1.387 & $1.036-1.855$ & 0.0278 \\
\hline Neutrophils > ULN & 1.681 & $1.225-2.306$ & 0.0013 \\
\hline $\mathrm{LDH}>1.5 \times \mathrm{ULN}$ & 2.221 & $1.461-3.378$ & 0.0002 \\
\hline Baseline SLD & 1.227 & $1.077-1.397$ & 0.0021 \\
\hline \multicolumn{4}{|l|}{ Variable $(N=310)^{b}$} \\
\hline TIMP-1 & 1.522 & $1.122-2.065$ & 0.0070 \\
\hline OPN & 1.611 & $1.161-2.236$ & 0.0043 \\
\hline ECOG PS 1 vs 0 & 1.485 & $1.090-2.023$ & 0.0121 \\
\hline Diagnosis-to-treatment time $<1$ year & 1.798 & $1.346-2.401$ & \\
\hline Neutrophils > ULN & 1.634 & $1.163-2.296$ & 0.0047 \\
\hline $\mathrm{LDH}>1.5 \times \mathrm{ULN}$ & 2.320 & $1.490-3.614$ & 0.0002 \\
\hline Baseline SLD & 1.221 & 1.069-1.395 & 0.0032 \\
\hline
\end{tabular}

Abbreviations: $\mathrm{CAF}=$ cytokines and angiogenic factors; $\mathrm{Cl}=$ confidence interval; $\mathrm{ECOG}$ $\mathrm{PS}=$ Eastern Cooperative Oncology Group performance status; $\mathrm{HR}=$ hazard ratio; $\mathrm{IL}=$ interleukin; $\mathrm{LDH}=$ lactate dehydrogenase; $\mathrm{NEU}=$ neutrophils; $\mathrm{OPN}=$ osteopontin; $\mathrm{SLD}=$ sum of longest diameters; TIMP-1 = tissue inhibitor of metalloproteinase-1; ULN = upper limit of normal.

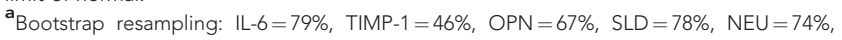
$\mathrm{LDH}=92 \%$, ECOG PS $=53 \%$

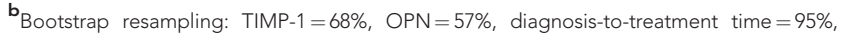
$\mathrm{SLD}=69 \%, \mathrm{NEU}=62 \%, \mathrm{LDH}=91 \%, \mathrm{ECOG} \mathrm{PS}=68 \%$.

observed with our CAF model, the incorporation of interleukin-6, osteopontin, or SLD resulted in an obvious separation of the prognosis for patients categorised as intermediate risk by the IMDC criteria (Figure 2C illustrates OS by IMDC risk groups plus SLD).

Association of CAFs with SLD and nonindependent IMDC parameters. We investigated associations between the seven initial CAFs and SLD, as well as the IMDC parameters that were not found to be independent predictors in our patient set (haemoglobin, platelets, and calcium). Six of the seven CAFs (all but E-selectin) showed statistically significant but generally weak positive correlations with baseline SLD (highest $R$ was 0.41 , for osteopontin), supporting a prognostic significance for the selected CAFs that goes well beyond a mere reflection of tumour burden (Supplementary Table 2). Moderate negative correlations were seen between the variables haemoglobin and osteopontin $(R-0.52$, $P<0.0001)$ and interleukin-6 $(R-0.51, P<0.0001)$, and a positive but weaker correlation between platelets and interleukin-6 ( $R$ 0.41, $P<0.0001$ ) (Supplementary Table 3), suggesting a partial causal relationship for these CAFs with the anaemia and thrombocytosis usually found in patients with aggressive RCC. There was no correlation with calcium for any of the CAFs.

\section{DISCUSSION}

This retrospective analysis evaluated seven preselected CAFs relevant to mRCC biology (Tran et al, 2012) and identified three (osteopontin, interleukin-6, and TIMP-1) as strongly prognostic for OS and independent of established clinical criteria. Two aspects of this analysis differentiate our study from previous research to identify prognostic, circulating biomarkers (Negrier et al, 2004; Montero et al, 2009; Pena et al, 2010). First, our strategy included CAF screening, selection, and validation, and used specimens from two separate, relatively large clinical trials (Tran et al, 2012). Second, the CAF analyses were performed under robust CLIA conditions. Results from three independent platforms were highly correlated (Tran et al, 2012), supporting the notion that any CLIA- 
A

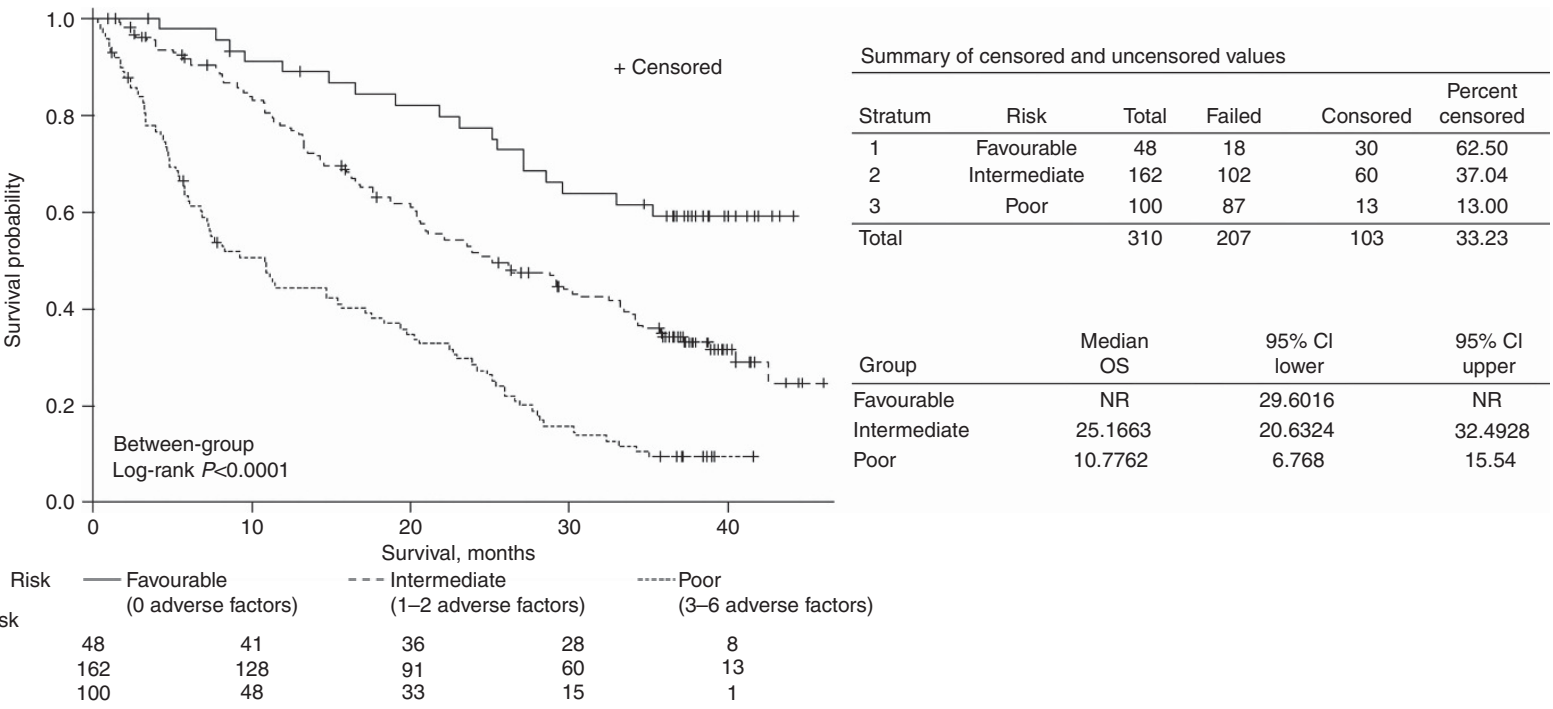

Favourable

Poor

B

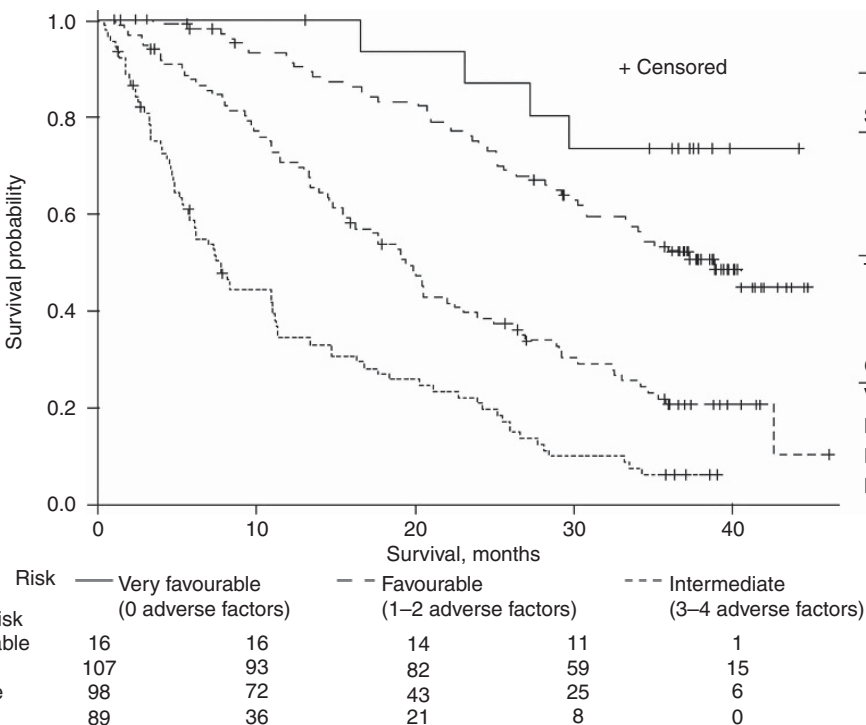

Summary of censored and uncensored values

\begin{tabular}{lccccc} 
Stratum & Risk & Total & Failed & Consored & $\begin{array}{c}\text { Percent } \\
\text { censored }\end{array}$ \\
\hline 1 & Very favourable & 16 & 4 & 12 & 75.00 \\
2 & Favourable & 107 & 50 & 57 & 53.27 \\
3 & Intermediate & 98 & 74 & 24 & 24.49 \\
4 & Poor & 89 & 79 & 10 & 11.24 \\
\hline Total & 310 & 207 & 103 & 33.23 \\
& & & & \\
& & & & & \\
Group & Median & OS & lower & upper \\
\hline Very favourable & $\mathrm{NR}$ & 27.1047 & $\mathrm{NR}$ \\
Favourable & 38.8665 & 30.7187 & $\mathrm{NR}$ \\
Intermediate & 19.3511 & 15.4086 & 22.8994 \\
Poor & 7.655 & 5.2895 & 10.9405
\end{tabular}

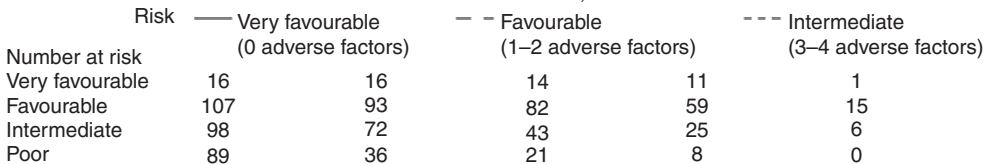

Poor

(5-7 adverse factors)

C

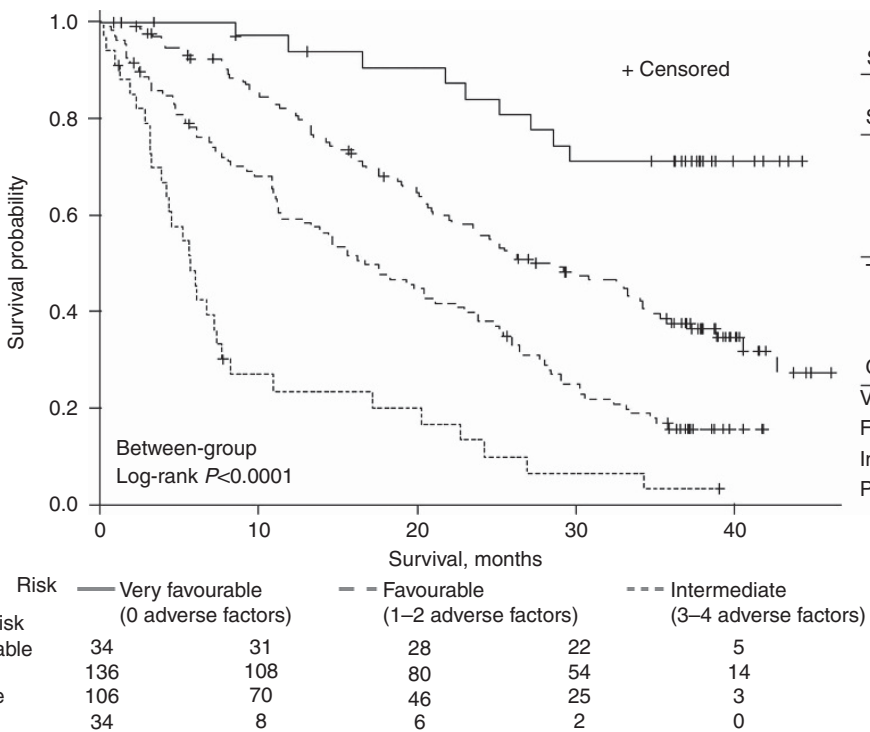

\begin{tabular}{|c|c|c|c|c|c|}
\hline Stratum & Risk & Total & Failed & Consored & $\begin{array}{l}\text { Percent } \\
\text { censored }\end{array}$ \\
\hline 1 & Very favourable & 34 & 9 & 25 & 75.53 \\
\hline 2 & Favourable & 136 & 81 & 55 & 40.44 \\
\hline 3 & Intermediate & 106 & 86 & 20 & 18.87 \\
\hline 4 & Poor & 34 & 31 & 3 & 8.82 \\
\hline \multicolumn{2}{|l|}{ Total } & 310 & 207 & 103 & 33.23 \\
\hline Group & \multicolumn{2}{|c|}{ Median } & \multicolumn{2}{|c|}{$\begin{array}{c}95 \% \mathrm{Cl} \\
\text { lower }\end{array}$} & $\begin{array}{c}95 \% \mathrm{Cl} \\
\text { upper }\end{array}$ \\
\hline Very favo & \multicolumn{2}{|c|}{ NR } & \multicolumn{2}{|c|}{ NR } & NR \\
\hline Favourab & \multicolumn{2}{|c|}{28.8131} & \multicolumn{2}{|c|}{22.1437} & 34.1355 \\
\hline Intermedi & \multicolumn{2}{|c|}{16.6571} & \multicolumn{2}{|c|}{11.4333} & 22.8994 \\
\hline Poor & \multicolumn{2}{|c|}{5.7166} & \multicolumn{2}{|c|}{3.8768} & 7.3593 \\
\hline
\end{tabular}

Number at risk
Very favourable

Favourable

Intermediate

Poor

34

Figure 2. OS by (A) IMDC risk groups, (B) CAF model with IL-6, and (C) IMDC risk groups plus SLD. Adverse factors for (A) PS (0 vs $>0)$, diagnosis-totreatment time ( $<1$ year), haemoglobin $(<L L N)$, calcium ( $>$ ULN), neutrophils ( $>$ ULN), platelets $(>U L N)$; (B) PS $(0$ vs $>0)$, diagnosis-to-treatment time (<1 year), neutrophils (>ULN), SLD (> median), LDH>1.5 $\times$ ULN, OPN, IL-6, TIMP-1; (C) as (A) above plus SLD (> median). CAF=cytokines and angiogenic factors; $\mathrm{Cl}=$ confidence interval; IMDC=International Metastatic RCC Database Consortium; LDH=lactate dehydrogenase; LLN=lower limit of normal; NR, not reached; OS=overall survival; PS=performance status; SLD=sum of longest diameters; ULN=upper limit of normal. 
certified assay suitable for routine measurement of osteopontin, interleukin-6, and TIMP-1 could be clinically useful. However, 'high' assay-specific levels would need to be defined for tests other than the SearchLight used here (Tran et al, 2012).

Although similar to other phase 3 clinical trials in the frontline mRCC systemic treatment setting the VEG105192 study only included patients with ECOG PS $0-1,15 \%$ of our set had poor prognosis per IMDC criteria. Therefore, we grouped ECOG PS as 0 vs $>0$ (instead of $0-1$ vs 2-higher) in our CAF model (and also for the IMDC), and based the risk groups on this categorisation. When individual CAFs were evaluated in multivariable stepwise models that included the preselected treatment and clinical prognostic factors as variables, high levels of five CAFs (osteopontin, interleukin-6, TIMP-1, interleukin-8, and HGF) showed association with poor OS. However, only osteopontin, interleukin-6, and TIMP-1 were confirmed in the complete model (which included all CAFs, treatment, and clinical variables). Other groups have suggested that interleukin-8 and HGF, and also VEGF, are associated with prognosis and even response and resistance to VEGF signalling pathway inhibitors (Escudier et al, 2008; Escudier et al, 2009; Huang et al, 2010; Nixon et al, 2013), but we did not confirm independent prognostic value for any of them in the presence of the other stronger CAFs and clinical variables.

Our results confirm and substantially expand previous studies showing that high levels of interleukin-6 and TIMP-1 are associated with poor OS in patients with mRCC (Negrier et al, 2004; Montero et al, 2009; Pena et al, 2010). Negrier et al (2004) reported a negative association with survival for high serum levels of interleukin-6 after analysis of 25 factors that included clinical variables, and circulating VEGF and interleukin-10, in 138 patients with mRCC treated with interleukin-2, interferon- $\alpha$, or the combination. A separate study showed similar findings for plasma TIMP-1 in 63 patients in the sorafenib phase 3 TARGET trial, but not for VEGF, carbonic anhydrase IX, or Ras p21 (Pena et al, 2010). However, to the best of our knowledge, we are the first to report on the independent prognostic value for OS of plasma osteopontin specifically in mRCC.

Beyond their usefulness as biomarkers, CAFs are biologically active mediators with potential to affect tumour behaviour and aggressiveness and serve as surrogates for pathways or mechanisms impacting response and resistance to treatments (Tran et al, 2012; Zurita et al, 2012). Osteopontin, interleukin-6, and TIMP-1 are known to be involved in pro-inflammatory, pro-tumourigenic, prometastatic, and immunomodulatory processes in cancer progression (Bellahcene et al, 2008; Jones et al, 2011; Ries, 2014), which may drive some of the clinical and laboratory manifestations of RCC aggressiveness and may help explain why the CAFs show superior prognostic ability. We found moderately negative correlations for interleukin- 6 and osteopontin with anaemia, and a weaker positive correlation for interleukin-6 with thrombocytosis. Interleukin-6 is considered an autocrine growth factor in mRCC (Miki et al, 1989), associated with decreased T-cell-mediated immunity (Narita et al, 2013) and a paraneoplastic systemic inflammatory response that includes fever, weight loss, elevated serum C-reactive protein, anaemia, and occasional thrombocytosis (van Rossum et al, 2009). However, the specific activities of osteopontin and TIMP-1 most relevant for RCC biology are not well characterised (Kallakury et al, 2001; Matusan et al, 2006).

Another important finding of our work is the prognostic value of pretreatment tumour burden, which we found stronger than that of haemoglobin, calcium, and platelets, even independent from that of the CAFs, and able to improve the C-index of the IMDC classification. Two smaller studies have evaluated the impact of baseline SLD on survival in patients with mRCC previously untreated with VEGF inhibitors, and in both cases found it significant even after adjusting for established risk scores (Basappa et al, 2011; Iacovelli et al, 2012). Even without including CAFs, a purely clinical model that incorporates SLD together with LDH, diagnosis-to-treatment time, neutrophil count, and PS performed noticeably better than that of the IMDC, and should be considered as an alternative worthy of comparison.

Limitations of this study include its retrospective nature, missing CAF data in $21 \%$ of patients, minimal racial diversity (mostly whites), survival estimates that may not be representative of the current RCC treatment landscape with the availability of new agents, and lack of external validation. Future research integrating genomic analysis will help assess whether some of these CAFs may reflect distinct mutational profiles or their biological consequences in RCC. Regardless, our results support the use of circulating osteopontin, interleukin-6, and TIMP-1 to better stratify patients by risk and to provide more accurate counselling on treatment and prognosis. Those biomarkers, together with SLD and the selected established clinical parameters, improved predictive accuracy relative to the IMDC model and should be considered for prospective incorporation into $\mathrm{mRCC}$ clinical trials for independent validation. We realise, however, the difficulties involved in the routine clinical implementation of the measurement of three CAFs for prognosis. Because interleukin- 6 links critical aspects of mRCC biology with response to treatment, it could be prioritised.

\section{ACKNOWLEDGEMENTS}

This study was sponsored by GlaxoSmithKline; pazopanib is an asset of Novartis AG as of 1 March 2015. Medical editorial assistance for the manuscript was provided by William Sinkins, $\mathrm{PhD}$, of ProEd Communications, Inc., Beachwood, Ohio, and Sai Krishna Arepalli, PhD, of Novartis Healthcare Pvt. Ltd.

\section{CONFLICT OF INTEREST}

AJ Zurita, HT Tran, RA Figlin, TE Hutson, and JV Heymach report no potential conflicts of interest. CN Sternberg reports having received personal fees from Novartis, GlaxoSmithKline, Astellas, Pfizer, and Bayer. RC Gagnon, Y Liu, AM D’Amelio Jr, and LN Pandite were employees of GlaxoSmithKline during the time of study conduct and initial manuscript development.

\section{REFERENCES}

Basappa NS, Elson P, Golshayan AR, Wood L, Garcia JA, Dreicer R, Rini BI (2011) The impact of tumor burden characteristics in patients with metastatic renal cell carcinoma treated with sunitinib. Cancer 117(6): 1183-1189.

Bellahcene A, Castronovo V, Ogbureke KU, Fisher LW, Fedarko NS (2008) Small integrin-binding ligand N-linked glycoproteins (SIBLINGs): multifunctional proteins in cancer. Nat Rev Cancer 8(3): 212-226.

Choueiri TK, Garcia JA, Elson P, Khasawneh M, Usman S, Golshayan AR, Baz RC, Wood L, Rini BI, Bukowski RM (2007) Clinical factors associated with outcome in patients with metastatic clear-cell renal cell carcinoma treated with vascular endothelial growth factor-targeted therapy. Cancer 110(3): 543-550.

Escudier B, Eisen T, Stadler WM, Szczylik C, Oudard S, Staehler M, Negrier S, Chevreau C, Desai AA, Rolland F, Demkow T, Hutson TE, Gore M, Anderson S, Hofilena G, Shan M, Pena C, Lathia C, Bukowski RM (2009) Sorafenib for treatment of renal cell carcinoma: final efficacy and safety results of the phase III treatment approaches in renal cancer global evaluation trial. J Clin Oncol 27(20): 3312-3318.

Escudier BJ, Ravaud A, Négrier S, Szczylik C, Molins JB, Bracarda S, Pisa P, Gaudreault J, Bajetta E (2008) Update on AVOREN trial in metastatic renal cell carcinoma (mRCC): Efficacy and safety in subgroups of patients (pts) and pharmacokinetic (PK) analysis. J Clin Oncol 26(90150): 5025-5025. 
Harrell Jr FE, Lee KL, Mark DB (1996) Multivariable prognostic models: issues in developing models, evaluating assumptions and adequacy, and measuring and reducing errors. Stat Med 15(4): 361-387.

Heng DY, Xie W, Regan MM, Harshman LC, Bjarnason GA, Vaishampayan UN, Mackenzie M, Wood L, Donskov F, Tan MH, Rha SY, Agarwal N, Kollmannsberger C, Rini BI, Choueiri TK (2013) External validation and comparison with other models of the International Metastatic Renal-Cell Carcinoma Database Consortium prognostic model: a population-based study. Lancet Oncol 14(2): 141-148.

Heng DY, Xie W, Regan MM, Warren MA, Golshayan AR, Sahi C, Eigl BJ, Ruether JD, Cheng T, North S, Venner P, Knox JJ, Chi KN,

Kollmannsberger C, McDermott DF, Oh WK, Atkins MB, Bukowski RM, Rini BI, Choueiri TK (2009) Prognostic factors for overall survival in patients with metastatic renal cell carcinoma treated with vascular endothelial growth factor-targeted agents: results from a large, multicenter study. J Clin Oncol 27(34): 5794-5799.

Huang D, Ding Y, Zhou M, Rini BI, Petillo D, Qian CN, Kahnoski R, Futreal PA, Furge KA, Teh BT (2010) Interleukin-8 mediates resistance to antiangiogenic agent sunitinib in renal cell carcinoma. Cancer Res 70(3): 1063-1071.

Iacovelli R, Lanoy E, Albiges L, Escudier B (2012) Tumour burden is an independent prognostic factor in metastatic renal cell carcinoma. BJU Int 110(11): 1747-1753.

Jonasch E, Futreal PA, Davis IJ, Bailey ST, Kim WY, Brugarolas J, Giaccia AJ, Kurban G, Pause A, Frydman J, Zurita AJ, Rini BI, Sharma P, Atkins MB, Walker CL, Rathmell WK (2012) State of the science: an update on renal cell carcinoma. Mol Cancer Res 10(7): 859-880.

Jones SA, Scheller J, Rose-John S (2011) Therapeutic strategies for the clinical blockade of IL-6/gp130 signaling. J Clin Invest 121(9): 3375-3383.

Kallakury BV, Karikehalli S, Haholu A, Sheehan CE, Azumi N, Ross JS (2001) Increased expression of matrix metalloproteinases 2 and 9 and tissue inhibitors of metalloproteinases 1 and 2 correlate with poor prognostic variables in renal cell carcinoma. Clin Cancer Res 7(10): 3113-3119.

Manola J, Royston P, Elson P, McCormack JB, Mazumdar M, Negrier S, Escudier B, Eisen T, Dutcher J, Atkins M, Heng DY, Choueiri TK, Motzer R, Bukowski R. International Kidney Cancer Working G (2011) Prognostic model for survival in patients with metastatic renal cell carcinoma: results from the international kidney cancer working group. Clin Cancer Res 17(16): 5443-5450.

Maroto P, Rini B (2014) Molecular biomarkers in advanced renal cell carcinoma. Clin Cancer Res 20(8): 2060-2071.

Matusan K, Dordevic G, Stipic D, Mozetic V, Lucin K (2006) Osteopontin expression correlates with prognostic variables and survival in clear cell renal cell carcinoma. J Surg Oncol 94(4): 325-331.

Miki S, Iwano M, Miki Y, Yamamoto M, Tang B, Yokokawa K, Sonoda T, Hirano T, Kishimoto T (1989) Interleukin-6 (IL-6) functions as an in vitro autocrine growth factor in renal cell carcinomas. FEBS Lett 250(2): 607-610.

Montero AJ, Diaz-Montero CM, Millikan RE, Liu J, Do KA, Hodges S, Jonasch E, McIntyre BW, Hwu P, Tannir N (2009) Cytokines and angiogenic factors in patients with metastatic renal cell carcinoma treated with interferon-alpha: association of pretreatment serum levels with survival. Ann Oncol 20(10): 1682-1687.

Motzer RJ, Bacik J, Murphy BA, Russo P, Mazumdar M (2002) Interferon-alfa as a comparative treatment for clinical trials of new therapies against advanced renal cell carcinoma. J Clin Oncol 20(1): 289-296.
Narita Y, Kitamura H, Wakita D, Sumida K, Masuko K, Terada S, Nakano K, Nishimura T (2013) The key role of IL-6-arginase cascade for inducing dendritic cell-dependent $\mathrm{CD} 4(+) \mathrm{T}$ cell dysfunction in tumor-bearing mice. J Immunol 190(2): 812-820.

Negrier S, Perol D, Menetrier-Caux C, Escudier B, Pallardy M, Ravaud A, Douillard JY, Chevreau C, Lasset C, Blay JY, Groupe Francais dI (2004) Interleukin-6, interleukin-10, and vascular endothelial growth factor in metastatic renal cell carcinoma: prognostic value of interleukin6-from the Groupe Francais d'Immunotherapie. J Clin Oncol 22(12): 2371-2378.

Nixon AB, Halabi S, Shterev I, Starr M, Brady JC, Dutcher JP, Hopkins JO, Hurwitz H, Small EJ, Rini BI, Febbo PG, George DJ. Oncology ACT (2013) Identification of predictive biomarkers of overall survival (OS) in patients (pts) with advanced renal cell carcinoma (RCC) treated with interferon alpha (I) with or without bevacizumab (B): Results from CALGB 90206 (Alliance). J Clin Oncol 31(15).

Pena C, Lathia C, Shan M, Escudier B, Bukowski RM (2010) Biomarkers predicting outcome in patients with advanced renal cell carcinoma: results from sorafenib phase III Treatment Approaches in Renal Cancer Global Evaluation Trial. Clin Cancer Res 16(19): 4853-4863.

Ries C (2014) Cytokine functions of TIMP-1. Cell Mol Life Sci 71(4): 659-672.

Sternberg CN, Davis ID, Mardiak J, Szczylik C, Lee E, Wagstaff J, Barrios CH, Salman P, Gladkov OA, Kavina A, Zarba JJ, Chen M, McCann L, Pandite L, Roychowdhury DF, Hawkins RE (2010) Pazopanib in locally advanced or metastatic renal cell carcinoma: results of a randomized phase III trial. J Clin Oncol 28(6): 1061-1068.

Sternberg CN, Hawkins RE, Wagstaff J, Salman P, Mardiak J, Barrios CH, Zarba JJ, Gladkov OA, Lee E, Szczylik C, McCann L, Rubin SD, Chen M, Davis ID (2013) A randomised, double-blind phase III study of pazopanib in patients with advanced and/or metastatic renal cell carcinoma: final overall survival results and safety update. Eur J Cancer 49(6): 1287-1296.

Tran HT, Liu Y, Zurita AJ, Lin Y, Baker-Neblett KL, Martin AM, Figlin RA, Hutson TE, Sternberg CN, Amado RG, Pandite LN, Heymach JV (2012) Prognostic or predictive plasma cytokines and angiogenic factors for patients treated with pazopanib for metastatic renal-cell cancer: a retrospective analysis of phase 2 and phase 3 trials. Lancet Oncol 13(8): 827-837.

van Rossum AP, Vlasveld LT, Vlasveld IN, Jansen PM, Dik WA, Hooijkaas H, Castel A (2009) Granulocytosis and thrombocytosis in renal cell carcinoma: a pro-inflammatory cytokine response originating in the tumour. Neth J Med 67(5): 191-194.

Zurita-Saavedra Y. Liu, Lin Y, Tran HT. VEG105192 Team and investigatorsPandite LN, Heymach JV (2012) Multivariate analysis of cytokines and angiogenic factors (CAFS) and established prognostic parameters in metastatic renal cell carcinoma (mRCC) patients (PTS) receiving pazopanib or placebo. Ann Oncol 23(suppl 9): ix261.

Zurita AJ, Jonasch E, Wang X, Khajavi M, Yan S, Du DZ, Xu L, Herynk MH, McKee KS, Tran HT, Logothetis CJ, Tannir NM, Heymach JV (2012) A cytokine and angiogenic factor (CAF) analysis in plasma for selection of sorafenib therapy in patients with metastatic renal cell carcinoma. Ann Oncol 23(1): 46-52.

This work is published under the standard license to publish agreement. After 12 months the work will become freely available and the license terms will switch to a Creative Commons AttributionNonCommercial-Share Alike 4.0 Unported License.

Supplementary Information accompanies this paper on British Journal of Cancer website (http://www.nature.com/bjc) 